\title{
A Critical Review of the Role of Repair Cafés in a Sustainable Circular Transition
}

\author{
Rikke Marie Moalem ${ }^{1, *}$ and Mette Alberg Mosgaard ${ }^{2}$ \\ 1 Department of Planning, Aalborg University, 2400 Copenhagen, Denmark \\ 2 Department of Planning, Aalborg University, 9000 Aalborg, Denmark; mette@plan.aau.dk \\ * Correspondence: rikkekr@plan.aau.dk
}

Citation: Moalem, R.M.; Mosgaard, M.A. A Critical Review of the Role of Repair Cafés in a Sustainable Circular Transition. Sustainability 2021, 13, 12351. https://doi.org/10.3390/ su132212351

Academic Editor: Adriana Del Borghi

Received: 30 September 2021

Accepted: 2 November 2021

Published: 9 November 2021

Publisher's Note: MDPI stays neutral with regard to jurisdictional claims in published maps and institutional affiliations.

Copyright: (c) 2021 by the authors. Licensee MDPI, Basel, Switzerland. This article is an open access article distributed under the terms and conditions of the Creative Commons Attribution (CC BY) license (https:// creativecommons.org/licenses/by/ $4.0 /)$.

\begin{abstract}
Extending the useful life of consumer products is a critical element in the circular economy. Although commercial repair is an established part of the global economy, the repair is often conducted informally. This means that non-commercial repair ecosystems exist, including the international network of repair cafés, spreading worldwide to over 2000 repair cafés in 37 countries (April 2021). As the first review on this topic, this article investigates and gains more knowledge about repair cafés, and critically assesses their role as a sustainability initiative, i.e., how the concept may translate into a broader sustainability context. A systematic literature review (2010-2020) was conducted, including 44 articles in descriptive and content analyses. The bibliometric data revealed an increase in the number of publications on repair cafés, particularly over the last four years, indicating that repair cafés as a research topic have started to gain attention, and this is likely to grow in numbers. However, the significant number of different places of publication indicates that this is not (yet) a well-established field with defined research channels. The content analysis revealed that the concept has spread to a range of different contexts, beyond the original scope, influencing the mindset and acts of a broad field of practitioners. This indicates a wide range of possibilities for the expansion of the concept of repair cafés, bringing different expectations on calling into question the future role of repair cafés. However, the aims of the people involved in repair cafés span from the altruistic and strategic, over personal gains, to critical consumer, financial and educational aims. This may challenge repair cafés' future role(s), i.e., ambitions set by the international organisation of repair cafés. Notably, the ambition for actors at the micro-level is to feed in data on repair and achieve 'collaborative repair', as the aims of the people involved are complex, and their expectations lack alignment, both vertically and horizontally.
\end{abstract}

Keywords: repair café; actors; product repair; sustainability; circular economy

\section{Introduction}

The repair of broken and faulty products that would otherwise end up as waste can help keep materials in use for longer, making repair a key element in a circular economy strategy [1-3]. Furthermore, repairing an item uses less energy than new production [4]. In addition, repair is the preferable option compared to remanufacturing or refurbishment, as it uses less energy and material [2].

Repairing is defined as a 'correction of specified faults in a product' [5] (pp. 259-260). Thus, repair activities are performed at the product level, and rather than the entire product being discarded into a waste or recycling stream due to a worn or damaged part, repair activities enable the continuance of the product's life [2].

Although commercial repair is an established part of the global economy [6], repair can be conducted informally [2]. This contrasts with other value-retention processes, such as remanufacturing or refurbishment, which are typically conducted formally in industrial settings [2].

A range of different actors, spanning from industrial repairers (mostly B2B), manufacturers, retailers and after-sales services to independent repairers (small/local scale SMEs) 
at the consumer level, can conduct repairs. Examples of the latter include repair cafés, 'self-repair', and internet solutions, e.g., iFixit [7]. Thus, repair is and can be conducted both formally and informally, e.g., through self-repair and in repair cafés.

In Europe and in the United Sates, there has been a decrease in the number of repair enterprises, e.g., for consumer electronics as well as personal and household items, and only recently has it seemed that a slight reversion has occurred in the EU [8]. However, the global crisis has, together with an increased environmental awareness, led to an increased interest in repair in industrialised countries [9]. As an example, over the last ten years, community repair movements have expanded [10], including a growing grassroots movement to support the repair of consumer products [11]. This has created ecosystems of non-commercial repair, including repair cafés; however, those non-commercial repair activities are less well-documented [6].

From a historical perspective, the first repair café came to life in 2009, initiated by Martine Potsma, who organised the first repair café in Amsterdam in 2009. Prior to this, the founder had applied for funding from the Dutch Ministry for the Environment-a subsidy for environmental activities aimed at fostering innovative environmental thinking [12] (pp. 64-65). These funds enabled Martine Potsma to establish the Repair Café Foundation, a non-governmental organisation that provides information and guidance to local groups setting up repair cafés in their own neighbourhoods [12]. After one year, Martine Potsma helped to develop twenty repair cafés not only in the Netherlands but also across Europe and the United States [12]. Since then, the success has grown to include 2125 repair cafés in 37 countries (https: / / repaircafe.org/en/visit/) (accessed on 29 April 2021), meaning that the concept is still growing.

According to Rosner [12], the concept of repair cafés can be traced back to responses to the financial crisis in 2007-2008. However, according to the founder, 'it all started with the Repair Manifesto of Joanna van der Zanden of Platform21' (the anniversary symposium celebrating the ten-year anniversary of the Repair Café, October 2019, Amsterdam). The establishment was an attempt to 'reduce waste and actively engaging the public in sustainability' at the local level [13] (p. 210). According to the international organisation of repair cafés, repairs tend to be smaller jobs that people could do at home but never get around to doing. These include jobs too insignificant or unattractive to take to a professional seamstress or bike repair shop, for example, raising the saddle of a child's bike, fixing a loose reflector, mending a tire, or even work a seamstress has rejected (https: / /repaircafe.org/ wpcontent/uploads/2013/09/Information_package_Repair_Cafe_USA.pdf) (accessed on 13 March 2021). Thus repair cafés assist users in performing simple repairs that are not to be confused with professional repairers. The international Repair Café Foundation has the following goals: (a) to bring back repairing into local society in a modern way; (b) to maintain repair expertise and to spread this knowledge; (c) to promote social cohesion in the local community by connecting neighbours from very different backgrounds and with different motives with each other through an inspiring and low-key event (https:/ / repaircafe.org/ wpcontent/uploads/2013/09/Information_package_Repair_Cafe_USA.pdf) (accessed on 13 March 2021). Thus, repair cafés are examples of community repair in which the community aspect is in the foreground [10] and the drivers to repair are based on shared value creation or sustainable thinking [14].

\section{Product Repair, Sustainability and Circular Economy}

Circular economy (CE) is viewed as being an alternative to a traditional linear economy of 'take-make-dispose' [15]. Furthermore, CE is often presented in 'discourses' in relation to a sustainable future, with an aim to the accomplishment of sustainable development $[10,16]$. The term 'sustainable development' is a guiding principle for development containing three aims to be accomplished simultaneously: environmental quality, economic prosperity and social equity [17]. The concept of CE is connected to sustainability and sustainable development $[18,19]$, and is important for its ability to attract both business and policy communities to sustainability work [20]. 
In a $C E$, repair is one of the main environmental strategies for achieving 'stock optimisation and waste prevention', as it supports product lifetime extension [21]. For example, a successful repair can bring a product back into use [10]. Within a CE, the term 'slowing resource loops' is used to describe slowing effects achieved through long-lasting products and the extension if product life, e.g., through repair [22]. One barrier to achieving product life extension through repair is planned obsolescence. This term is used for 'purposely designing' a product that 'stops working, works less well, or cannot be repaired before the end of its expected lifetime' [23] (p. 1). It occurs in consumer products, such as washing machines, and also in smaller consumer goods, such as flat-screen TVs and consumer electronics, contributing to resource inefficiency [23], linking to the degrowth debate in terms of decoupling consumption and resources [24]. Furthermore, repair as a CE initiative has a local dimension to it [25]

From a CE perspective, 'design for disassembly' is a strategy for improving product reparability in which the need to disassemble products for repair, refurbishment and recycling is already considered in the product design phase [21]. In relation to this, repair data is an important resource in a circular economy because data can enable and support product reparability, and can thus accelerate the adoption of CE [26]. Data can be used to improve reparability, e.g., by informing product design and CE policies in regard to the durability and repairability of products [10]. Some community repair initiatives collect and share data, including Repair Café International [10]. The aim of the collection of data is to 'identify what needs to be done to make products more repairable, so they will contribute to a circular economy' [27] (p. 3).

However, the decision concerning whether to repair or not is initiated by the users of the products, making consumers' repair behaviour key to a sustainable transition [28,29]. At the consumer level, drivers and barriers to repair are affected by a variety of factors stemming from technical, emotional and value aspects [29], including a lack of financial means to buy new products, saving money [30] and increasing environmental awareness [14]. This has led to the emergence of consumer groups living less wasteful lifestyles, including 'self-repairers' [31].

With regard to developing CE solutions successfully, attention should be given to all three dimensions of sustainability [18,20,22]. With regard to this, van Buren et al. [32] use repair cafés as an example to illustrate that circularity is vivid in civil society, and not only in industry. Nevertheless, environmental concerns are often found to be favoured over environmental and social ones [16], including indicators for measuring CE at the micro level [33]. Further, consumers are rarely outlined as enablers of the $C E$, although the $C E$ operates at the micro-, meso- and macro-levels [16]. In addition, or maybe due to this, 'little is known about consumers' willingness to participate in [a CE]' [34] (p. 1), leaving behind a research gap regarding consumers' perspectives on CE [16] (p. 220).

This article sets out to investigate and gain more knowledge about repair cafés as a local sustainability initiative, and, on this basis, to critically assess the role of repair cafés in a circular sustainable transition. The latter includes a discussion on the ways in which local repair initiatives match the wider sustainability objectives formulated by the international Repair Cafés Organization.

This paper is organised as follows: Section 2 explains the methods used. Section 3 holds the descriptive analysis of the bibliometric results obtained in the review. Section 4 presents the content results, including a critical analysis of the results obtained in the literature review (as seen in the light of repair cafés and their role in a circular sustainable transition). Section 5 offers a critical discussion about the results, and Section 6 concludes the literature review.

\section{Research Methodology and the Framework of the Analysis}

The study presented in this article consists of a review of the literature on repair cafés. This literature review aims to create an overview of the scientific research on repair cafés that has been performed so far, including the identification of the themes and patterns in the 
literature [35]. Different approaches to literature reviews exist, and review methodologies include systematic, semi-systematic or integrative approaches [36]. The chosen method for conducting this study is systematic, which provides a summary of previous studies in the area [37]. According to Knapp [38], librarians possess important qualifications in interdisciplinary research in terms of identifying information and bridging different perceptions of qualified knowledge. Furthermore, library staff possess great professional insight into the use of search engines and relevant databases, and in organising knowledge, which qualifies them to take on roles in interdisciplinary research [38]. Thus, librarians assisted with this literature review, particularly with regard to the development of a strategy to obtain data in a systematic way, supporting an iterative process. In order to secure a systematic review, the research process was designed with inspiration from Snyder [36], Fink [39], and Briner and Denyer [40]; see Figure 1.

\begin{tabular}{|c|c|c|}
\hline \multicolumn{2}{|r|}{ Steps } & \multirow{2}{*}{$\begin{array}{c}\text { Research } \\
\text { Development of a search strategy supportive of a systematic review }\end{array}$} \\
\hline 1. & Strategy to obtain the data & \\
\hline & 2. Initial review & $\begin{array}{l}\text { What defines repair cafés? Who participates? What is repaired? What is } \\
\text { gained from a sustainability and circular perspective? }\end{array}$ \\
\hline \multicolumn{2}{|r|}{ 3. Objective } & $\begin{array}{l}\text { Obtain an overview of the scientific research on repair cafés and on this } \\
\text { basis, critically asses the role of repair cafés in a circular sustainable } \\
\text { transition }\end{array}$ \\
\hline \multicolumn{2}{|r|}{ Criteria for considering studies } & $\begin{array}{l}\text { Develop criteria for considering studies, including databases, words and } \\
\text { search strings }\end{array}$ \\
\hline & Data collection & Collecting data and exclusion of repeated articles \\
\hline & Quality assessment & $\begin{array}{c}\text { Screening/reading (ensuring that all the obtained studies meet the search } \\
\text { criteria) }\end{array}$ \\
\hline & Analytic framework & Analysing material to develop an analytical framework. \\
\hline & Preparation of results & $\begin{array}{l}\text { Preparing results for the descriptive analysis of the bibliometric results } \\
\text { obtained for the systematic review and content analysis }\end{array}$ \\
\hline
\end{tabular}

Figure 1. The research process inspired by [36,39-41].

In the following is a short description of the eight steps in the research process, including the criteria for the consideration of the studies. This also includes the words used in the search string, and examples of how this resulted in different hits and made the process iterative. The word search was undertaken in four academic search engines (Scopus, Web of Science [WoS], EBSCOhost, and Google Scholar).

The first step in the process included the development of a systematic search strategy to obtain data in which the overall aim was to create a strategy which allowed for the repeated running of cycles and the securing of documentation of the process. This process resulted in a search strategy template supporting an iterative process. The second and third steps in the review process included the initial review and the definition of the research problem to be studied, the objectives, and the criteria for considering the studies. This resulted in framing the study: What defines repair cafés? Who participates? What is repaired? What is gained from a sustainability and circular perspective? The objective of obtaining an overview of existing peer-reviewed studies on repair cafés includes addressing the role of repair cafés from a sustainability and circular perspective. Thus, the 'what, who and why, drivers and barriers to repair' guided the content analysis. The criteria for considering the studies were that the papers should include 'repair café*', 'repair café*' AND CE OR sustainability OR waste. The fourth step included setting up the search criteria to obtain the data (see Figure 1). This step included predefining the search criteria, such as databases, words, search strings, document type, the time span for articles in the search and the language. The literature review was confined to scientific peer-reviewed articles, books, book chapters and proceedings. The keywords used in the search included 
'repair café*', 'sustainab", 'circular economy*' and 'waste'. These words were combined in different ways and search strings (Block 1: word OR word OR word AND, Block 2: word OR word OR word AND Block 3: word OR word OR word, etc.), e.g., 'repair café*', 'repair

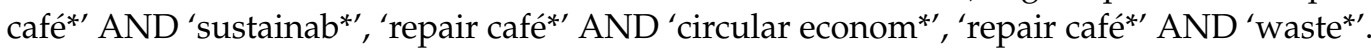

Search strings were used to create different search blocks in which we could narrow or broaden our search, e.g., by combining different search strings to different levels of searches in the databases. As an example, our initial search (Block 1) included only one search string (Scopus S1: 'repair café*'Abstract, title, keyword). This resulted in only eight articles. In order to obtain more articles, we expanded the search string to also include 'all fields' (Scopus S2: 'repair café*' 'all fields'), resulting in 26 articles. In another example (Block 2), we initiated the search to include one search string (WoS S1: 'repair café ${ }^{* \prime}$ ), providing us with only eight articles. In this case, the expansion (WoS S2: 'repair café*' 'all fields') only provided us with one extra article (9). The search template established a search structure, which allowed for spiraling out from databases covering broad and umbrella databases. The fifth step in the process included the initial search ('repair café*' AND sustainab*' OR circular econ*' OR 'waste*') in each of the three databases (Scopus, WoS, EBSCOhost), using the combination of 'repair café*' AND ('sustainab*' OR 'circular econom $^{* \prime}$ OR 'waste ${ }^{* \prime}$ ), which resulted in a total of 95 papers. Eliminating repeated articles across all of the databases resulted in a total number of 62 articles. Step six included a quality assessment to ensure that all of the papers fell into the category of peer-reviewed articles or proceedings, which resulted in a total number of 45 . A final read of the full paper (excluding those not meeting the established criteria) resulted in a total number of 41. Reasons for not meeting the criteria at this final stage included only the abstract being in English, and the term 'repair café' only occurring in the reference list and not in the main text.

In order to ensure that the review had come to completion, a final search was performed in the search engine Google Scholar, thus repeating steps five and six. This included combining the broadest search string ('repair café*') with a search on an umbrella search engine (Google Scholar), resulting in 943 hits. Excluding the repeated papers and articles not meeting the search criteria resulted in a total number of three articles $(2+1$ early release 2021). Inserting relevant papers (3) that were not included in the initial search left us with a total number of 44 articles (Scopus, WoS, EBSCOhost 41; Google Scholar 3). In order to supplement the search, the cited references in the already-identified articles were checked, as recommended by Webster and Watson [37]. This did not lead to any additional publication being included in the review, indicating that the existing peer-reviews on repair cafés had been obtained.

Inspired by Zacho and Mosgaard [41], the seventh step in the process included the development of an analytic framework for organising, classifying and analysing the literature. The framework resulted in two main categories-descriptive elements and concept categories-and six subcategories; see Table 1.

The first category concerns descriptive elements encompassing the number of publications distributed over time; the journals in which the articles were published; the countries in which the articles were published, including countries with the greatest number of publications; and finally, the publications' dispersal according to the subject area. The second category concerns the content of the literature. Based on Webster and Watson [37], this part include themes and concepts for the organisation and analysis of the data. The process of defining the categories and subcategories was iterative, going back and forth during the reading of the literature [41]. The themes and patterns for the content results and analysis were identified using a matrix organizing the content of the 44 articles, searching for themes and patterns. The results from this categorization are provided in the Appendix $B$.

Thus, the analysis is divided into two parts. The first part constitutes a descriptive analysis of the bibliometric results obtained in the review, including basic statistics. The second part constitutes the bibliometric results obtained, forming the basis of the analysis of the content of the articles included in the literature review, critically assessing the central 
elements of the repair cafés in the light of the goals of their own organization and in relation to their role in a sustainable development transition.

Table 1. The analytical framework guiding the analysis.

\begin{tabular}{|c|c|}
\hline Categories & Subcategory \\
\hline $\begin{array}{l}\text { Descriptive analysis of the bibliometric results } \\
\text { obtained in the review }\end{array}$ & $\begin{array}{l}\text { - Number of publications distributed over } \\
\text { time } \\
\text { - Journals in which publications are pub- } \\
\text { lished } \\
\text { - Countries in which the greatest number of } \\
\text { articles were published } \\
\text { Publications dispersal according to subject } \\
\text { area }\end{array}$ \\
\hline Content results and analysis & $\begin{array}{l}\text { - What constitute repair cafés } \\
\text { - Repair cafés-who and why }\end{array}$ \\
\hline
\end{tabular}

\section{Descriptive Analysis of the Bibliometric Results Obtained in the Review}

In this section are the basic statistics of the years and sources of the publication, and the countries of affiliation, including the countries with the greatest number of publications and the publications' dispersal according to their subject areas.

\subsection{Dispersal over Time}

The first bibliometric analysis investigated how publications related to repair cafés are dispersed over time (Figure 2).

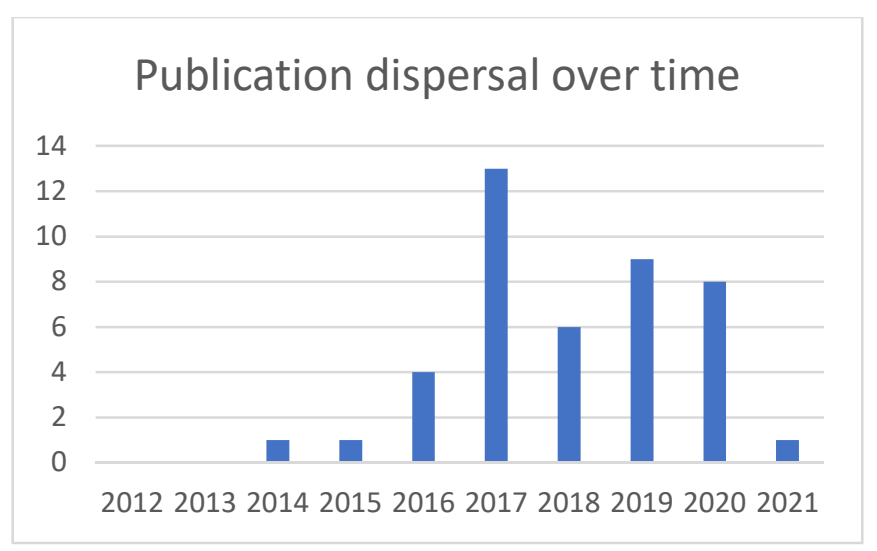

Figure 2. Repair café literature dispersal over time (indexed in Scopus, WoS, EBSCOhost, 2010-2020).

In the graph, one article from 2021 occurred in the search (indexed 2010-2020). The explanation is that this article appeared in the search, as it was a 2021 forthcoming article.

The graph illustrates an increase in the number of articles published, especially in the last four years (2017-2020), in which 40 out of the total number of 44 articles were published. This indicates that the repair café as a research topic has started to gain attention, and is likely to grow in numbers. The Action Plan adopted by the European Commission in 2015 led to increased attention on repair, which could have influenced the number of articles published.

\subsection{Source of the Publications}

The second analysis investigated the source of the publications (Appendix A: Figure A1). What catches the eye is the great number of different places of the publications. Forty 
different publishers published the 44 articles. Only four journals had more than one publication. The greatest sources of publications were Energies (2), European Planning Studies (2), the Journal of Cleaner Production (2) and publications in the Handbook of Sustainable Product Design. This indicates that this research field is not a well-established one with fixed research channels yet.

\subsection{Countries of Affiliation}

The third bibliometric analysis investigated how the countries of affiliation are dispersed geographically (indexed in Scopus, 2010-2020). From a geographical point of view, it can be noticed that most of the articles came from Germany $(13 \%)$ and the United Kingdom $(12 \%)$, which dominated the field, followed by Austria $5 \%$, the United States $(4 \%)$, China and Finland (3\%), and the rest were below 2\% (Netherlands, Romania, Austria, Belgium, Canada, Greece, Italy and New Zealand).

\subsection{Documents by Subject Area}

The fourth bibliometric analysis investigated how the publications are dispersed according to their subject area (Figure 3). Sixteen types of subjects were retrieved, with the most frequent being social science, representing $27 \%$ of the total publications indexed in Scopus. This was followed by environmental science (13\%), business management and accounting (12\%), engineering (9\%), economics, econometrics and finance $(8 \%)$, the arts and humanities $(7 \%)$, and energy $(7 \%)$. The rest of the subject areas had insignificant shares: mathematics ( $2 \%)$; medicine (2\%); and finally nursing, agricultural and biological sciences, decision science, earth and planetary sciences, materials science and psychology, each with $1 \%$.

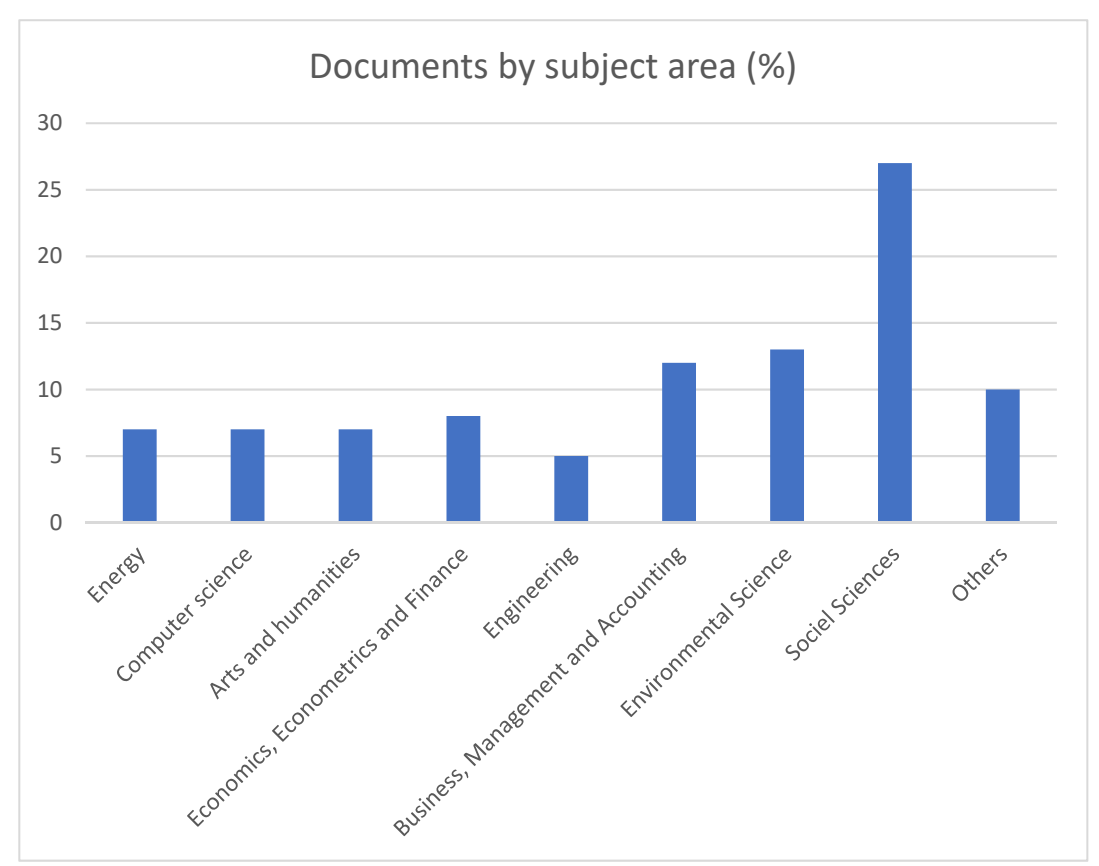

Figure 3. Number of documents according to their subject area (indexed in Scopus, 2010-2020).

\section{Content Results and Analysis}

This section presents, and critically asseses, repair cafés and their role in a circular sustainable transition, based on the results obtained in the literature review. The themes and patterns were identified using a categorisation matrix on the 44 articles obtained in this literature review. The content analysis is divided into two parts. First, it investigates how the literature presents the more organisational and structural elements of repair cafés (what constitutes repair cafés?), such as the format of repair cafés, the products brought for repair, and the location and geographical distribution. The second part of the content 
analysis investigates (a) how actors are presented, including a critical view on the actors and their reasoning as to why (not) they engage in repair at repair cafés, and (b) how the purpose(s) of repair cafés are presented in the existing literature. Those elements lay the foundation for the discussion, critically assessing the role of repair cafés in a circular sustainable transition. In particular, this includes the ways in which local repair café initiatives match the wider sustainability objectives formulated by the international repair cafés organization. Appendix B provides an overall overview of the content results which lay the foundation for the content analysis.

\subsection{What Constitutes Repair Cafés-Organisational and Structural Characteristics}

The first analysis of the content examined what constitutes repair cafés, including the format, the products brought to repair cafés, and their location and geographical distribution; see Appendix B, Table A1: Content results-What constitutes repair cafés?

\subsubsection{The Format of Repair Cafés}

Six articles addressed the format of repair cafés in different ways, but primarily in relation to the set-up and procedures, the time and frequency of the events, and social elements.

\section{Set-Up and Procedures}

Seven articles addressed the format of repair cafés in relation to the set-up and procedures. The format of repair cafés is viewed as 'quite straightforward' [42], including seating and table arrangements which are 'similar' [43], and consisting of volunteers offering help sitting by tables where signs above or on the tables indicate the type of goods in need of repair [43] (p. 78). In one article, the set-up also included a reading table with books about repair, as the repair café event took place at a library [44]. One article addressed the procedural aspects of repair cafés as a 'step-by-step' procedure, with visitors explaining the problem to the volunteers before they are directed to the appropriate repair station where a volunteer expert awaits them to diagnose the problem, gives advice on how to repair the item and, if feasible, carries out the repair [42]. In addition to this 'step-by-step' procedure, it is stressed that repairing requires a 'range of gestures, tools and competences, and also emotional engagement' [45] (p. 7), as repair work often 'develops in unpredictable ways, requiring a range of capabilities'.

However, five articles also highlighted the more social aspects of repair café set-ups, including the fact that the materials, tools and know-how to fix broken consumer products are being provided to the visitors [46]. Furthermore, repair cafés constitute places where visitors can bring their broken items and attend free of charge [42,46-49], thus touching upon the more social aspects of the set-up, in particular the inclusion of people with a low income.

\section{Temporary vs. Fixed}

Four articles addressed the format of repair cafés in relation to time and frequency, where the latter seems to differ.

In some cases, repair cafés are organised several times a month, and sometimes weekly [48], contrasting to another case where the event was held just three times a year [44]. One article addressed that the events take place for a restricted period of time, usually three to five hours [43] (p. 78). One article addressed repair cafés as constituting 'pop-up' events, which are often held on a regular basis [42] (p. 644), thus addressing repair cafés as events that are 'temporary and unexpected' but also as something more 'fixed', contrasting with the temporal aspect.

\section{Social Elements (Contributing to the Strengthening of Social Cohesion)}

In addition to the more formal requirements for repair, the repair café set-up was also described as supporting the social aspects of a community [49]. One article addressed this aspect in the following way: 'Irrespective of the location, usually coffee and cake or 
other beverages and snacks are provided to create a sort of café atmosphere even when not actually taking place in cafés' [43] (p. 78). As an example, there may be a refreshment table with coffee, tea and donuts [44]. This suggests that elements in the set-up contribute to the relational side of communities, supporting the social function of repair cafés. The latter was not a part of the original concept of repair cafés but rather something which became clear over time. Pesch et al. [48] stated it this way:

Originally, the concept of repair café was invented as a way to reduce waste and to extend the lifetime of products. Moreover, it was intended to revive 'forgotten' technical skills that are required to repair broken down appliances. Over time, it became clear that the repair cafés also have a strong social function. (p. 307)

Summing Up the Format

The overall format of repair cafés is described as quite 'straightforward', including the physical set-up and procedures. However, there are also variations. Firstly, the frequency of the events can vary from weekly to just a few times a year. In addition, the event format seems to constitute both 'pop-up' events and more stationary events, and at times a mix of both, thus addressing repair cafés as events that are 'temporary and unexpected' but also as something more 'fixed'. The latter contrasts with the temporal aspect. In common, the repair café set-up encompasses social elements with the potential to contribute to social cohesion and inclusion.

\subsubsection{Products Brought to Repair Cafés}

Sixteen articles addressed the type or age of products brought to repair cafés in varying ways.

\section{Products and Types}

Repair cafés have a general focus on electronic products $[30,50,51]$, and receive and recover broken [42] or defective everyday objects $[9,47,52]$. One article indicated that the products brought for repair include items that are 'highly valued' [46] (p. 934).

In the category of electronic products, media technologies are one of the most common types of products brought to repair cafés [47]. This includes computers and computer equipment [9,47,52], laptops [52], smartphones and mobile phones [14,47,52,53], radios [47,52], and slide projectors [52].

Household items are also commonly brought to repair cafés. Firstly, these include household electrical and mechanical devices $[14,45,48]$, in particular small domestic appliances [50] like toasters [44,53] and vacuum cleaners [44]. Secondly, clothes [30,44,45,48,53]including shirts with loose buttons [44] and the 'hem of their trousers' [53] (p. 70)-are brought to repair cafés, which gives a glimpse of the type of repair carried out on clothes.

Finally, bikes [30,45,48,54,55], furniture [48] and toys [30,48] are repaired there.

The products brought to repair cafés constitute both old and new devices [43,52], e.g., 'They bring with them new devices such as laptops and smartphones as well as old ones like slide projectors and radios' [43] (p. 79). Whether the products brought to repair cafés are successfully repaired is only dealt with at a more general level, e.g., 'a variety of people brought defective everyday objects and devices that were (mostly successfully) repaired with the free assistance of the students and other 'experts" [43] (p. 189).

\section{Summing Up the Products' Types and Ages}

The type of products repaired in repair cafés depends on the physical set-up, including the aim of the specific repair café and the repairer's expertise. Based on the 16 articles addressing the products brought to repair cafés for repair, there seems to be a preponderance of electronic products, including media technology and household items. However, there are examples of other products, such as clothes, bicycles, furniture or toys, as well. Two articles note that the products brought to repair cafés constitute a mix of old and new devices. Common to the articles is that none seem to address quantitative measures, such 
as the numbers of products brought to repair cafés or the types or brands of products, including more detailed measures on the age of the products and whether the products are repaired or not.

\subsubsection{Location and Geographic Distribution}

Seven articles addressed the geographical aspects of repair cafés, in particular, their dispersal over time and the type of location in which repair cafés occur.

Type of Location

Repair cafés constitute new and widespread events $[43,52]$ which are often held at fixed locations in neighbourhoods [45]. The most common types of locations are makerspaces [56], cafés and community centres [43,47,52,57]. However, five articles addressed alternative examples, including the public library, hosted by the librarians, where repairing stations were set up in the library's meeting room and outside on the front lawn [44]. In addition, they were held in a pub; in an art studio [47]; in a university context [43]; in an old, temporarily unoccupied building [52]; and finally at a public school, hosted by the schoolteachers [55]. In one article, the organisers of the repair event had put some thought into the choice of location: 'We thought the idea of using buildings that were not new and that were temporarily unoccupied would perfectly fit with the idea of not throwing away goods that can still be used' [52] (p. 189), thus addressing the type of location for the repair café as both 'fixed' and 'temporary', expanding the location to also include temporarily unoccupied buildings.

\section{Geographical Distribution}

The concept of repair cafés originated in the Netherlands in 2009. Repair cafés are based on Netherlands experiences, and the concept is spreading worldwide [9]. Three articles specified the geographical spread to Western Europe and North America [43,47,52], including many industrialised countries [45].

In line with this, one article ascribed the trend of 'making' to a trend occurring in the West [58]. In addition, others dealt with how fast the concept is growing, e.g., that the concept is both 'new and widespread' [52], and from 2009-2017, almost one thousand repair cafés had been set up across 24 countries [42]. Thus, the geographical dispersal encompasses aspects of both scale and time, indicating that the concept is growing in popularity at a certain speed.

\section{Summing Up the Type of Location and Geographical Distribution}

The concept of repair cafés had its origin in the Netherlands, but is a growing concept that is spreading worldwide. However, the trend of 'making' seems to occur mainly in the West. In terms of location, repair cafés are most commonly held in cafés, community centres or makerspaces. However, a range of alternative solutions is also appearing in the literature, testifying to the fact that repair cafés can be established in a multitude of locations. Thus, repair cafés are held in neighbourhoods in existing premises, and include both public and private spaces. Seven articles addressed the geographical aspects of repair cafés, in particular, their dispersal over time and the type of location in which repair cafés occur.

\subsection{Actors: Who, and Why (Not) Do They Engage in Repair at Repair Cafés}

The second analysis of the content investigated how actors are presented, including a critical view on the actors and their reasoning as to why (not) they engage in repair at repair cafés. The actors in repair cafés are people who voluntarily offer help in either organising the repair events or in the repairing process for visitors seeking help; see Appendix B, Table A2: Content results-Actors; who and why (not). 


\subsubsection{Volunteers}

The volunteers consist of both the organisers of the repair cafés and the repairers who do the repairs in repair cafés. The volunteers are mostly retired people [43], and are often repairers [45], but also constitute a range of other people, including artists [43], librarians [44], teachers [55] and university employees [43,47], thus constituting a broad palette. The aims of the people involved in repair cafés consist of differing motivation and ambitions [48]; they are, in fact, complex [43], and include the 'conservation of resources, waste prevention, appreciation of the apparatus, technical empowerment, having fun repairing things and economic pressure' [48] (p. 84). Kannengießer [43] notes that this complexity goes against previous studies by Charter and Kieller [57], who stated that 'volunteers act altruistically and that their personal gain is not important to them' [43] (p. 82).

\section{Organisers}

The organisers constitute a range of different actors from both the private and public sector, and the aims of the people involved with repair cafés are complex. The motives to engage are addressed as both altruistic and strategic, in particular in relation to the public sector. Thus, the motives seem to span broadly within the context of sustainability, and consist of both altruistic and professional gains. Eleven articles addressed the organisers of repair cafés, including their aims, roles and barriers to engagement.

Eleven articles addressed and characterised the volunteers of repair cafés, including who they are and what drives them to engage. Characteristic to the organisers of repair cafés is that they are often skilled volunteers [46] and repairers [45]. However, the organisers also include librarians from a public library [44], teachers from primary and secondary schools [55], university employees, retired teachers [43,47] and artists [43].

The motives and ambitions that underlie the activities of the people that run the cafés vary [48]. From one perspective, the underlying motives are altruistic, including a way of 'giving back' to the community and a way to encourage others to live more sustainably [46]. Others addressed motives that relate more to a 'strategic shift', particularly within the public sector, including school and education, public libraries, and city planning, as well as finding new ways of achieving school learning goals [55] and identifying future roles for public libraries, including the testing of alternative uses [44]. Furthermore, establishing a bike repair café can be part of an overall strategy to enhance a district's transformation, including an attempt to contribute to an overall improvement in the 'quality of life' in a district [54].

Finally, the organisers engage because they aim to build a network among people who know how to repair as they pursue the repairing of media technologies as an 'act of empowerment' [43]. In relation to the latter, one article addresses the role of managers or founders in such makerspaces as 'gatekeepers to circular practices' [56] (p. 283), thus emphasising that organisers may play a societal role in transitioning towards a more circular society. Despite the importance of the role of the organisers, the work done by the organiser(s) can easily be taken for granted or not noticed until it is needed [58]. Organisers face constant work to keep the initiative running [58]. The role involves a wide range of tasks, including finding a location, advertising for volunteer experts, general advertising, and conducting public relations, etc. [52]. Thus, there is the risk that the organisers will burn out.

\section{Repairers}

The accompanying motives for the repairers vary, but generally they build upon a range of personal gains, from learning and keeping up with skills, to having fun and socialising, to bringing a level of contentedness to everyday life for both pensioners and the unemployed. Repairers are made up of students, and retired and unemployed people with varying motivation. Although repairers constitute experts, they may also include people with varying skills and knowledge, who relate more broadly to extending the lifetime 
of products, including knowledge related to product maintenance. The accompanying motives include a range of personal gains, including contentedness in everyday life for both pensioners and the unemployed.

In the literature, repairers are described as taking on two roles: one relates to the practical side of repairing (e.g., diagnosing and carrying out the repair). The other relates to the knowledge that repairers gain with regard to planned obsolescence in electronics. Six articles addressed some of the accompanying motives for the involvement of the repairers in repair cafés, including who they are, the tasks undertaken, and their roles.

The repairers include both retired and unemployed people [43] and students [52], and the tasks include diagnosing the problem, giving visitors advice on how to repair, and carrying out the repair [42]. Commonly, repairers are addressed as 'experts' [42,52] with differing expertise, including specialists such as electricians, tailors, carpenters and bicycle mechanics [48]. In some cases, the repairers in repair cafés have gone through formal training [45], thus stressing the need for competences. However, one article addressed that 'experts' or 'repairers' may also include persons who possess skills which relate more broadly to extending the lifetime of products, including specific maintenance skills. Examples from the texts include students with skills related to the maintenance of specific products, such as laptops, smartphones and radios [52], in addition to students with varying levels of skill and knowledge related to bike repair and sewing fabrics, for example [52]. Thus, repairers constitute specialists, but may also include people with varying levels of skills and knowledge about repair and maintenance. For example, the useful life of clothes can often be extended easily [59].

Repair cafés provide an opportunity for retired and unemployed people to find tasks to do, as well as a space to socialise [43]. Their motives vary, but mainly consist of personal interest. Examples of this include gaining knowledge in a personal interest related to specific product groups, e.g., media technology, and having fun repairing [43]. As an additional benefit, repairing is a 'positive challenge' that may help in keeping retired people engaged [43]. Thus, valuable knowledge around repair is retained, and even updated. In relation to this, one article addressed that repairers in repair cafés contribute to identifying problems of planned obsolescence regarding electronics [60]. Thus, the role of the repairer may extend further than 'just' diagnosing and repairing. In particular, repairers may play an important role with regard to addressing specific problems concerning planned obsolescence. This may include the spotting of product weaknesses of which the producers are unaware.

\subsubsection{Visitors}

Common to visitors to repair cafés are the variety of people from all age groups, varying social backgrounds, and the gender distribution of both men and women. Although their motives vary, they can be categorised into three broader groups, including being a critical consumer, a financial perspective, and educational motives. Five articles addressed some of the accompanying motives for the involvement of the visitors, including who they are and what motivates them to visit repair cafés.

The visitors to repair cafés constitute a variety of people [52] from all age groups [43]. The visitors include men as well as women, who come from different social backgrounds [43], and students [55]. However, one article found that it was significant that people with a migration background rarely participate [43].

One motivation factor is having the perspective of a critical consumer. In particular, participants want to prolong the lifespan of existing products in order to avoid buying new [43,52], including reducing e-waste [52]. In addition, some visitors bring items to repair cafés to have them fixed, although they have already bought a replacement for them [45]. This finding, or behaviour, goes against Pesch et al. (2019), who state that 'Repair Cafés' core function-repairing broken products—can be seen as a clear example of substitution to buying products' [48] (p. 308). However, the underlying reason for this behaviour is closely linked to everyday practices where 'the need of the object to be 
able to perform daily routines often is greater than waiting for the object to be fixed' [45] (p. 8). If the object is not fixed, visitors can 'dispose of it with good conscience' [45] (p. 8). In contrast, if the object is fixed, visitors donate it to the organisers. This means that not all repairs are examples of substitutions for buying (new) products. A second perspective addressed relates to monetary motivations [43]. In particular, repair cafés provide repairs for free, allowing people with a low income to avoid costs [48]. Finally, Schulte et al. (2018) addressed education as an accompanying motive, as students visit repair cafés to achieve some of their learning goals.

\subsubsection{Subculture of the Repairers}

Actors in repair cafés are part of a larger (sub)culture, but they also share an identity with a smaller local group.

Repair is not a new phenomenon; the novelty is that repairing (through repair cafés) has become public [52]. Repair cafés are, on the one hand, actors 'on their own', organised by and for local residents in one particular neighbourhood. On the other hand, repair cafés constitute a collective, a repair subculture, constituting a group of people within a culture that differentiates itself from the parent culture to which it belongs. As addressed in one article 'we cannot talk about sustainability without a culture of repairing' [52] (p. 187), bridging repair cafés to a 'subculture' of repair, e.g., as part of 'grassroots movement' [61], 'grassroots innovation movement' [62] and 'grassroots innovation' [63]. Other articles addressed the collective action in ways that are more specific, e.g., as part of a 'maker movement' [14,64], 'modifiers and fixers movement' [14] and 'repair movement' [42]. Thus, repair cafés are a bridge to the culture of 'making' in which some makers are 'critical makers' [43] and part of a do-it-yourself (DIY) activism [58]. Others may 'just' be DIY citizens [48] in a DIY culture [65] and a 'making culture' [58]. One may say that for the 'critical makers', repair cafés may constitute a local sustainability initiative (LSI) $[48,63]$, and for others, repair cafés may 'just' constitute 'community workshops'or 'makerspaces' [56]. Thus, repair cafés seem to have found their way to the fulfilment of different roles in society, including the provision of a space in which both the critical consumer and the DIY citizen can partake.

\section{Summing Up the Actors in Repair Cafés}

The actors in repair cafés encompass a range of different actors, and the aims of the people involved in repair cafés are complex; however, there are some general characteristics. The main drivers for organisers consist of both altruistic and strategic aims, whereas the driving forces for repairers seem to relate more to personal gains. Finally, visitors are driven by critical consumer, financial and educational motives. However, repair cafés are also addressed in relation to large global movements. Thus, actors in repair cafés are part of a larger (sub) culture, but they also share an identity within a smaller local group.

\subsubsection{Purpose(s)}

The final part of the content analysis investigates the ways in which the purpose(s) of repair cafés are presented in the existing literature. Nineteen articles addressed the different purposes served by repair cafés; see Appendix B, Table A3: Content analysis-The purpose(s) of repair cafés

\section{Waste Reduction and Product Longevity}

From an environmental perspective, the purpose of repair cafés is seen as 'bottomup environmentalism' [66], motivating consumers towards product repair [67]. Repair cafés enable communities to reduce their environmental burden by offering them the opportunity to repair items [50], and in particular, a way to reduce waste [48,49], including e-waste [51], and to extend the lifetime of products [48], thus providing citizens with a 'voice' in the sense of combatting waste, environmental degradation and shared repair problems [46]. The use and support of activities like repair cafés may also serve a higher 
purpose, such as influencing planned obsolescence [60] and improving product reparability and longevity [68]. Thus, initiatives like repair cafés can eventually assist consumers in achieving more independence [60].

\section{Strengthening Social Cohesion}

From a social perspective, repair cafés provide a place to meet [30,47,48,53,54]. More specifically, repair cafés are public sites of repair [42], in which people can meet to repair [52] free of charge [42,46,48], or free of any direct exchange [46]. Thus, repair cafés provide a space for freely accessible meetings, including the avoidance of costs for people with a low income [48], thus contributing to the strengthening of social cohesion [46,48]. One article addressed this particularly in relation to an improvement of social cohesion among volunteers and visitors [48]. In another case, the repair café was established at a university campus, constituting a meeting point where students, university staff and neighbouring residents can meet [54]. However, repair cafés are also addressed as places where 'people who might otherwise be sidelined are getting involved again' [42] (p. 645). Thus, in some cases, the key to social cohesion is the 'space', and repairing is secondary.

\section{Pedagogical Aspects of Repair Movements}

Repair cafés also serve pedagogical purposes, both as a phenomenon and as an activity. In particular, repair cafés are useful in environmental communication pedagogy, where they can serve as a point of departure for deeper discussion concerning production, consumption and disposal [52], in addition to examples of how environmental communication can be put into practice [52], such as being a subject in practical seminars. Partly linked to this, repair cafés are noted as places for 'testing assumptions around the connection between learning skills and long-term change' [42] (p. 644). Thus, repair cafés can serve the purpose of teaching and as a place for research [54], and thus become an extended environmental communication and research platform.

\section{Revive Forgotten Skills and Hands-On Learning}

From learning, knowledge, skill-sharing and empowerment aspects, repair cafés support the development of local socio-technical skills [14]. They do so by taking a handson approach to the pedagogy of repair [42]. Particularly, skill-sharing events [52,58] where people exchange, access, or transfer knowledge [30] contribute to the revival of 'forgotten' technical skills [48] and empower people to repair [51]. Thus, the purpose is twofold; learning new and reviving forgotten skills, and a matter of giving back 'the power to repair' and thus gaining (some) control over products. However, in order to reach (the majority) of those aims, both the repairer and the visitor must engage in the repair together.

\section{Collaborative Aspects}

Another element addressed relates to the 'collective' side of repair and repair cafés, particularly addressing that repair cafés are not merely a free service provider for repair, to which visitors come to sit passively while the repairers 'fix it for you'. In contrast, it is a place where people are 'invited in to learn' [65], to 'collaboratively repair' [45] and engage in 'shared repairing' [46]. From this perspective, the idea is not to provide a 'free service centre' but rather to 'help people to help themselves' [48,52], and to help each other to repair broken products [30]. In this way, people meet to repair together, to learn something together and to become conscious [52]. Thus, in some respects, there is a distinction made between visitors (in the passive form) and participants. This may help explain why some articles addressed the visitors as 'participants'.

\section{Service Aspects}

In contrast to the collaborative purpose, the articles also addressed repair cafés as 'service providers', providing materials, tools and know-how in a community space [46]. More explicit repair cafés are a non-market-based solution to repair [14], offering 'self- 
repair services' [31] with 'professional assistance' [54], and workshops with experts [31]. In addition, repair cafés provide materials and tools [46], and a 'space', which together provide a valuable service to the community and the public $[46,68]$. In line with the service aspect, one article addressed repair cafés as a 'sharing platform' in line with, e.g., a Library of Things, Retroy and the Fixit clinic [46]. However, the article stresses that the service provided can, and should be, distinguished from other types of sharing platforms. Finally, repair cafés are addressed as 'third party service providers' and 'autonomous loop operators' in relation to CE [69] (p. 1263), particularly in relation to slowing and closing product and related material loops, as those require service operations, such as repair. However, due to the informal character of the relationship among actors in this laissez-faire architecture, a central coordinator fails to receive this feedback. This is noted as a 'lost opportunity' [69], as valuable knowledge is being lost.

\section{Change Agents}

The concept of repair cafés has found its way into a range of different contexts, from rethinking the role of community spaces and the way we plan our cities, to pedagogical aspects, political participation, and finally to broader political reflections concerning societal shifts to repair as a societal imperative, and the driving forces behind it. Feeding into this discussion of repair cafés as part of a broader network of subcultures, seven articles addressed repair cafés as 'change agents', particularly in the sense that the concept has influenced the mindset and acts of a broad field of practitioners. This includes rethinking community spaces [44], in which librarians transferred the idea of repair cafés into a public library context. The librarians took on the role of the organisers of the event, including advertising for volunteers to help others fix their broken items, and later hosting the repair event [44]. In this case, the aim was not to have more things repaired, but rather to contribute to rethinking the future role of public libraries, including alternative uses. In another example, 'the Computing Repair café' [55] involved pedagogical aspects of repairing, and more specifically a transfer of ideas to computing education [55], where the hands-on approach from repair cafés was used as a means to achieve high-level learning goals and problem-solving. As a side effect, the students began to change their view on technology, including their own use pattern, and began to see their habit of often buying a new phone in a wider ecological context [55], thus taking on a pedagogical approach to repair cafés. Pattillo [49] suggest implementing the concept of repair cafés internally in a nursing faculty, focusing on, i.e., printers, penlights, scrubs, or stethoscopes.

In addition, Graziano and Trogal [42] addressed this 'mindset shifting' ability of repair cafés: 'The Repair Café teaches people to see their possessions in a new light. And, once again, to appreciate their value' [42] (p. 645). Furthermore, the repair café helps change people's mindset, which is 'essential to kindle people's enthusiasm for a sustainable society' [42] (p. 645).

A third example involved the case of 'The Bicycle Repair Café' [54], in which the concept of repair cafés was transferred into a broader context of sustainable architecture and green mobility. The bike repair café constitutes a meeting point for cyclists, and includes professional assistance for minor bicycle repair [54]. The aim of the bike repair café is to serve as 'a place for research and teaching, as well as an object of investigation for sustainable architectural concepts' [54] (p. 1) and to 'enhance the district's transformation ... creating a space to reflect environmental problems to be solved' [54] (p. 1), thus constituting a rethinking of the way in which we plan our cities and city districts. Other studies addressed the role of repair cafés in dealing critically with issues of materiality and (over) consumption [43,52] by referring to repair cafés as an innovative setting for environmental activism [52], in which 'people criticize the capitalistic consumer society and develop practices aimed at sustainability' [43] (p. 78). This further highlights the relevance of repair cafés for social change, including the way in which repair cafés are used to 'lobby' for environmental protection (52], thus linking to broader aspects of political participation. In line with this, others explore some of the diverging political positions, contributing to 
'the shaping of the (rising) movement of repairers' [42] (p. 638), including the way in which these 'public sites of repair' [12] (p. 55) are contributing to a societal change, and more specifically 'the shift from repair seen as a family responsibility to societal imperative' [12] (p. 55), thereby addressing aspects related to the politics of collective repair.

\section{Summing Up 'Purpose(s)'}

Repair cafés serve different purposes for different people, spanning from environmental concerns, to strengthening social cohesion, to pedagogical purposes including ways to maintain repairing skills and carry out collaborative repairs, beyond repair cafés merely being a 'service' that is free of charge. In addition to this, it is impressive to find out how the concept of repair cafés has found its way into a range of different contexts, from rethinking the role of community spaces and the way we plan our cities, to pedagogical aspects and political participation, and finally to broader political reflections concerning societal shifts to repair as a societal imperative and the driving forces behind it. Feeding into this discussion of repair cafés as part of a broader network of subcultures, seven articles addressed repair cafés as 'change agents', particularly in the sense that the concept has influenced the mindset and acts of a broad field of practitioners.

\section{Discussion}

This section sets out to discuss how the concept of repair cafés speaks to the three parameters of sustainability (environmental, social and economic), followed by a critical assessment of local repair cafés' ability to meet the ambitions laid out by the international Repair Cafés Organisation. The discussion is based on the potentials and challenges for repair cafés in addressing sustainability-related issues, as addressed in the review.

\subsection{The (Potential) Role of Repair Cafés as a Local Sustainable Initiative in a Circular Transition}

When environmental concerns conflict with the social values of community repair, consumers are rarely outlined as enablers of the CE [16], although they may be addressed from the perspective of 'community involvement' [21]. Furthermore, little is known concerning consumers' willingness to participate in the CE [70]. In this CE strategy, community involvement can be achieved through 'the involvement of communities and different stakeholders in organizing sharing platforms and providing guidance on product repair and replacement' [21] (p. 196), bringing community repair into discourses on CE. In light of this, we critically assess how repair cafés may, or may not, contribute to this discourse.

From an environmental perspective, repair cafés provide local repair opportunities, which include areas lacking places to have repairs performed. However, with the present set-up, not all types of products are repaired in repair cafés. At present, repair cafés receive and recover broken [42] or defective everyday objects [9,47,52], and some repair cafés have a general focus on electronic products $[30,50,51]$. The type of products repaired in repair cafés also depends on other factors, such as what is brought to repair cafés and the experience of the repairers who volunteer [10]. In particular, if products are perceived to require special skills, such as mobile phones, and none of the repairers have this experience, the particular repair café is unable to repair mobile phones [10]. Thus, the present set-up may limit repair cafés' possibilities to expand product repair and boost their environmental contribution.

However, from a social perspective, repair cafés have a strong social function [48]. Common to repair cafés is that the set-up and procedures constitute social elements with the potential to contribute to social cohesion and inclusion (see Section 4.2.4), in particular by providing a place to meet and a space for socialising $[43,44]$, thus bringing a level of contentedness to everyday life for both pensioners and the unemployed. Furthermore, repair cafés provide places where people can bring their broken objects for repair, free of charge [42,46-48], avoiding costs for and including people with a low income [48]. However, the social function, which is embedded in the community aspect, may sometimes conflict with other core values, including those of the environment. As an example, it has 
been suggested that repair cafés could repair electronics salvaged from municipal e-waste recycling, with the aim of donating the repaired products to the underprivileged [10]. The latter complies with the core aims of the $\mathrm{CE}$ and community repair, but it was turned down as the initiative would 'pull' repair cafés more towards being a third-party service provider and 'intervene in the community function' of the repair café [10], thus illustrating that repair cafés have the potential to expand on the original idea, but individual repair cafés may prevent a situation in which the community aspect 'moves to the background' [10].

From an environmental and economic sustainability perspective, repair cafés are also viewed as taking on different roles, pulling them more towards being a 'third-party service provider' $[27,69]$. Obtaining repair data is an important resource in the CE [26]. Repairers in repair cafés obtain valuable knowledge regarding weak points in product or service design, bringing community repair into discourses on the CE, e.g., as 'third-party service providers' and 'autonomous loop operators' in relation to the CE [69] (p. 1263), and particularly in relation to slowing and closing product and related material loops, as those require service operations, such as repair. As an example, autonomous repair shops collect valuable information regarding weak points in product or service design, and develop innovative solutions: 'We [third-party service provider] are better in many things. I can solve problems that an Apple employee, the entire Apple store, would not even begin to understand. We can solve these because we are much more closely involved in the matter' [69] (p. 1263). However, due to the 'informal character' of the relationship among the actors in this 'laissez-faire' architecture, central coordinators fail to receive this feedback. The latter is seen as a 'lost opportunity' [69], as valuable repair knowledge is being lost. In line with the latter, the international organisation of repair cafés plays an important role in terms of collecting and reporting data for a greater purpose beyond that at the local level, as suggested by Potsma [27], as obtaining repair data is an important resource in the CE [26]. However, there is an 'unwillingness' amongst (some) volunteers to participate in collecting and reporting data for the monitoring of repairs [10]. Reporting data often conflicts with the practice of the repairers, and it takes up 'community time'. According to van der Velden [10], this exemplifies a 'socio-material entanglement of people and things', meaning that the material and the social in community repair cannot be separated [10]. This may challenge repair cafés to take on new roles in which the community aspect of repair is not in the foreground.

On the other hand, from a collaborative perspective, community repair in repair cafés provides an opportunity for local citizens to participate in a CE [10]. For example, repairers help to improve product reparability and longevity [68] while simultaneously pursuing their passion and having fun repairing things [48] (p. 87). Furthermore, repair cafés contribute to improving societal issues, such as social cohesion and accommodating people with a low income [48], by providing a free service not only to citizens but also to society, contributing to both social and economic sustainability. In addition, collaborative repair is seen as going 'far beyond the activity itself', including social issues such as quality of life, saving natural resources and the inclusion of excluded people [71]. From this collaborative aspect of repair, Hielsher et al. [45] stressed that the repair process can become 'equally important' to 'fixing the object', as the active engagement with an object can make people value the object. Thus, Hielsher et al. [45] recommend that repair cafés 'draw as much attention to the repair process as to its outcome' in their communication. However, in support of our results, Meißner [71] stresses that, in regard to collaborative repair, interaction requires social competences for both the repairer and the visitor, which cannot always be met.

\subsection{Local Repair Cafés' Ability to Meet the Ambitions Laid Out by the International Repair Cafés Organisation}

The International Repair Café Foundation has three goals. The findings in this review indicate that those goals are achieved to varying degrees. This is discussed in the following section. 
With regard to the first goal, 'to bring back repairing into local society in a modern way', it is particularly interesting to uncover the ways in which the concept has influenced the mindset and actions of a broad field of practitioners. As an example, the concept of repair cafés has found its way into a range of different contexts, from 'rethinking' the role of 'community spaces', i.e., future roles of public libraries [44], to the way we plan our cities, i.e., the bicycle repair cafés in a district's transformation [54] and political participation [52]. The latter includes broader political reflections concerning societal shifts from repair as a 'family responsibility' to repair as a 'societal imperative' [12] (p. 55). Further examples include repair cafés serving pedagogical purposes, both as an activity and a phenomenon, particularly in environmental pedagogy as a point of departure for 'deeper discussions' concerning 'production, consumption and disposal' [52], and as a place for 'testing assumptions around the connection between learning skills and long-term change' [42] (p. 644). Thus, the concept of repair cafés seems to flourish and expand to areas which may be beyond the original purpose, including teaching, research, and rethinking community spaces.

In regard to the second goal, 'to maintain repair expertise and to spread this knowledge', repair cafés seem to provide a good foundation for volunteer repairers with respect to maintaining and upgrading valuable repair knowledge. As an example, repairer are referred to as 'experts' [52], who identify problems of planned obsolesce [60], thus making repairers attractive knowledge partners [27,69]. However, for several reasons, repairers are challenged regarding the 'spreading' of this knowledge. From a collaborative aspect, visitors sometimes lack creativity [11] or interest in learning to perform repairs [43] which reflect that repair is a marginal activity [72]. In addition, a behavioural study on consumer engagement in the CE also revealed that 'repair decisions' are easily disrupted if arranging the repair requires effort [73] (p. 10) and if the cost of the repair is higher compared to a replacement [74]. Furthermore, sharing knowledge about repair requires social competences for both the repairer and the visitor, which cannot always be met [71].

Finally, in regard to the third goal, 'to promote social cohesion in the local community by connecting neighbours from very different backgrounds and with different motives with each other through an inspiring and low-key event', repair cafés contribute to the strengthening of social cohesion, including the avoidance of cost for people with a low income [48]. Furthermore, the actors seem to constitute a range of different players, and the visitors include men and women who come from different social backgrounds; only people with a migration background rarely participate [43]. Thus, the repair café contributes a strong social aspect, as well as sustainability. However, volunteers organise repair cafés, which involves a wide range of tasks [43]. This mean that the organisers face 'constant work' to 'keep the initiative running' [58]. The work performed by the organiser(s) can, however, easily be taken for granted or not noticed until needed [58]. Thus, there is a risk of organisers eventually burning out, even in a low-key event set-up as at present. Despite this, not much attention has been paid in the literature to how repair cafés can sustain themselves in the future.

\section{Conclusions}

The main goal of this paper was to provide an overview of the current academic literature on the topic of repair cafés. In total, 44 articles were included in the review for the period 2010-2020. The concept of repair cafés is addressed in a variety of ways in the reviewed literature, which has provided a unique opportunity to obtain a broad understanding of how the concept of repair cafés has developed up until now, particularly by providing us an opportunity to, on a broad foundation, to holistically assess and get a glimpse of where repair cafés may head in the future. This particularly concerns the role of repair cafés as a sustainability initiative and how the concept may translate into a wider sustainability context. 


\subsection{Bibliometric Analysis}

The bibliometric data revealed that there has been an increase in the number of publications on repair cafés, most significantly over the four years from 2016 to 2020, during which the number of published papers more than doubled. This indicates that the repair café as a research topic has started to gain attention, and is likely to grow in numbers. However, what really catches the eye in the bibliometric data is the great number of different places of publication. This indicates that this is not (yet) a well-established field with defined research channels. It further indicates that the concept of repair cafés contains a large variety of facets, which can be translated into a number of different contexts.

From a geographical point of view, it can be noticed that most articles came from Germany $(13 \%)$ and the United Kingdom (12\%), which dominate the field, followed by Austria 5\%, the United States (4\%), China and Finland (3\%), and the rest below $2 \%$ (Netherlands, Romania, Austria, Belgium, Canada, Greece, Italy and New Zealand).

\subsection{Content Analysis}

The overall format of repair cafés can be described as being quite simple, including the physical set-up and procedures. However, the events are addressed as both temporary and unexpected, and at times more fixed. In common, the repair café set-up constitutes social elements with the potential to contribute to social cohesion and inclusion.

The products brought to repair cafés for repair vary. However, electronic products seem to be the most dominant. Other examples include clothes, bicycles, furniture and toys, and a mix of both old and new items. However, from the perspective of the repair café 'setup', the types and volumes of products repaired in repair cafés depend on the local context, e.g., the physical set-up, the aim of the specific repair cafés, and the repairers' expertise. In particular, the latter seem to determine the types of products repaired. As noted by the international repair cafés organisation, repairs most often consist of smaller jobs which are too insignificant or unattractive to take to a professional repairer. Furthermore, repair cafés assist users in performing simple repairs on limited types of products. Therefore, repair cafés cannot stand alone, but rather serve as a supplement to home repair and the established system of professional repairers.

The concept originated in the Netherlands in 2009 and is spreading worldwide; on the other hand, however, it is also regarded as a trend of making occurring in the West. The latter indicates that repair cafés may follow economic prosperity and consumption patterns, and flourish more in industrial countries.

The actors in repair cafés constitute a range of different players with differing purposes and differing drivers to engage. Furthermore, the aims of the people involved are complex. However, there are some general characteristics. The main drivers for organisers consist of both altruistic and strategic aims, whereas the driving forces for repairers seem to relate more to personal gains. Finally, visitors are driven by critical consumer, financial and educational motives. What becomes apparent is that the actors in repair cafés share an identity within a smaller group at the local level, having both local and individual goals. At the same time, however, repair cafés are part of a broader culture of repairers, who have global goals. In that context, repair cafés constitute an innovative setting for environmental activism, contributing to a circular transition.

The purpose of the concept of the repair café is addressed in various ways, supporting all three aspects of sustainability, though the weight seems to be heavier on social aspects (i.e., contributing to social cohesion). However, the ambitions of the international organisation may be achieved to varying degrees. Particularly, the ambition for actors at micro level to feed in data on repair and the achievement of 'collaborative repair' seem more challenging to realize. One explanation is that the aims of the people involved are complex (i.e., consumers' (un)willingness to participate and repairers' pedagogical competences, or the lack thereof). Furthermore, expectations are not aligned, vertically nor horizontally.

Nevertheless, the findings also reveal the concept that repair cafés function as 'change agents', as the concept has spread to a range of different contexts, influencing the mindset 
and acts of a broad field of practitioners, spanning from the way we plan our cities (i.e., mobility) to pedagogical aspects, thus spreading beyond the original scope of the concept.

Thus, repair cafés holds the potential to playing different roles in sustainable CE transitioning, spanning all three legs of sustainability, to varying degrees.

This indicates a wide range of possibilities for the expansion of the concept of repair cafés, which bring both different expectations and call into question the future role of repair cafés.

Viewing repair cafes through the lenses of peer-reviewed literature omitted nonacademic experiences. Furthermore, academic publications may be lagging behind in this practice-based field. Thus, grey literature could bring exciting perspectives on the subject, i.e., strengthening the link between repair cafe experiences and product redesign.

Furthermore, investigating how the repair movement can be supported systematically may also be a critical research gap, including the ways in which future policy initiatives may support repair cafés.

Author Contributions: Conceptualization, R.M.M. and M.A.M.; methodology, R.M.M. and M.A.M.; software, R.M.M.; validation, R.M.M.; formal analysis, R.M.M.; investigation, R.M.M.; resources, R.M.M.; data curation, R.M.M.; writing — original draft preparation, R.M.M.; review, M.A.M.; visualization, R.M.M.; supervision, M.A.M. All authors have read and agreed to the published version of the manuscript.

Funding: The research in this paper is part of the project 'Fremtidens Intelligente Energi-og Ressourcesystemer (FUTURE), funded by Interreg, The Capital Region of Denmark, and Region Zealand (Interreg ID: NYPS 20201560).

Conflicts of Interest: The authors declare no conflict of interest.

\section{Appendix A. Bibliometric Results}

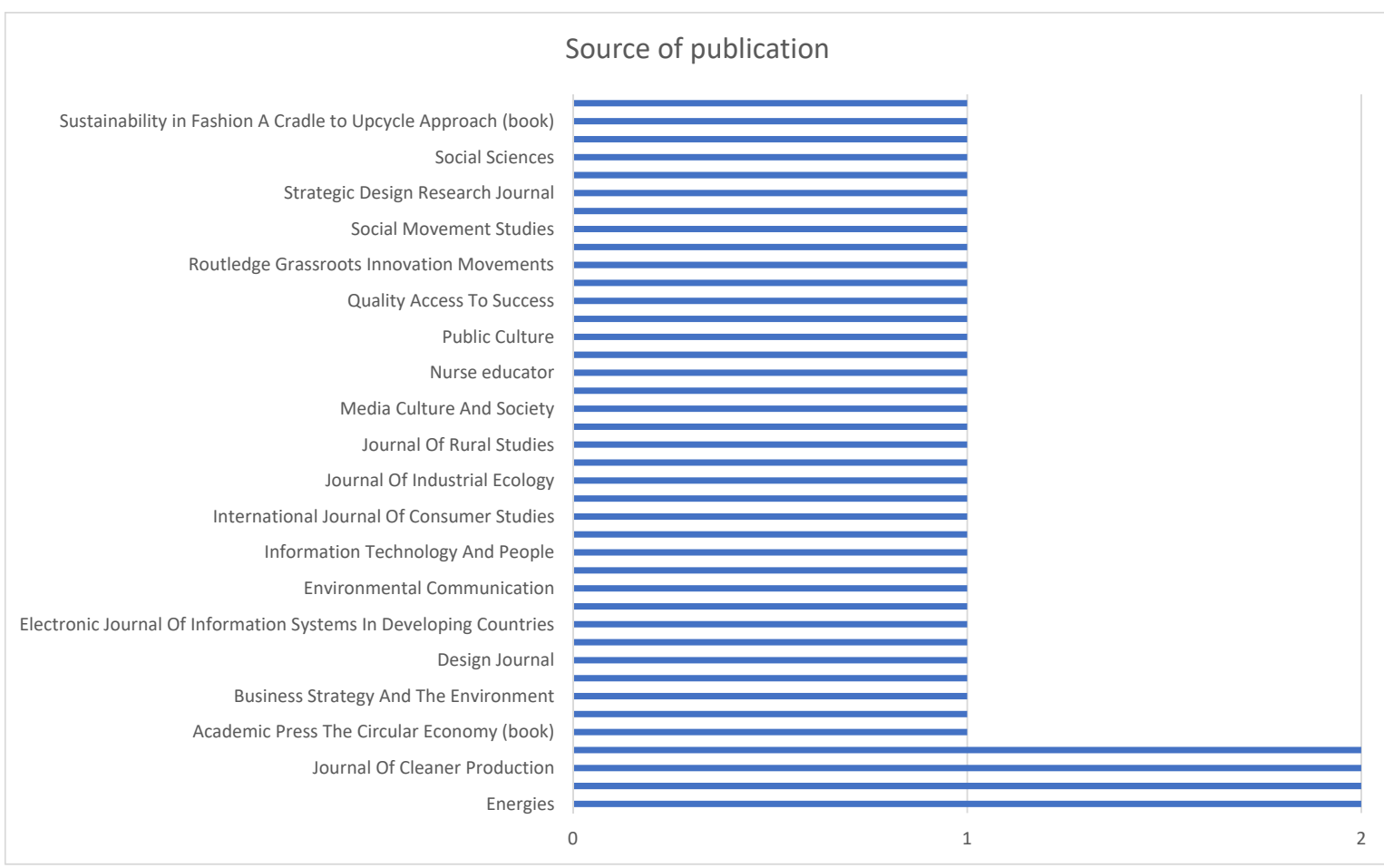

Figure A1. Sources of the publications. Journals that included repair café-related publications (indexed in Scopus, WoS, EBSCOhost, 2010-2020). 


\section{Appendix B. Content Results (Analytical Matrix)}

Table A1. Content results: What constitutes repair cafés?

\begin{tabular}{|c|c|}
\hline $\begin{array}{c}\text { Categories and Number of Articles } \\
\text { Addressing This }\end{array}$ & Results Obtained from the Text \\
\hline The format of repair cafés \#6 & $\begin{array}{l}\text { The format \#6 } \\
\text { 'Pop-up' events [42]; held on regular basis [42]; organised several times a month and sometimes } \\
\text { weekly [48]; events take place for a restricted period of time (usually three to five hours) [48]; } \\
\text { three times per year [44]; provides materials, tools and know-how [46] (p. 933); volunteers } \\
\text { diagnose, give advice, carry out the repair [42]; refreshments and a reading table with books from } \\
\text { the library about repairs [44] (p. 262); create a sort of café atmosphere [48,49]; seating and table } \\
\text { arrangements are similar [48]; free of charge [42,46-49] }\end{array}$ \\
\hline $\begin{array}{l}\text { Type of products brought to repair cafés } \\
\qquad \# 16\end{array}$ & $\begin{array}{c}\text { Types of products } \\
\text { Everyday objects [9,47,52]; 'broken items' [42]; mostly successfully repaired [52]; technical } \\
\text { gadgets [55]; media technologies being one of the most common [47]; computers [52]; computer } \\
\text { equipment [9]; laptops [43,52]; mobile phones [14,53]; smartphones [43,47,52]; radios [47]; old } \\
\text { radios or slide projectors [43,52]; electronic products [30]; electronic devices [51,55]; electrical } \\
\text { appliances [48]; broken household appliances [48]; household electrical and mechanical devices } \\
\text { [45]; other household items [45]; household appliances [14]; small domestic appliances [50]; } \\
\text { toasters [44,53]; vacuum cleaners [44]; clothes [30,45,48], bicycles [30,45,54,55]; toys [30]; highly } \\
\text { valued items [46] }\end{array}$ \\
\hline $\begin{array}{l}\text { Location and geographic distribution } \\
\qquad \# 8\end{array}$ & $\begin{array}{l}\text { Location and geographic distribution \#8 } \\
\text { New and widespread events [52]; at different types of location—very often in cafés [48,52] or } \\
\text { community centres [47,48]; in makerspaces [56]; at a public library [44]; in a pub [47]; in an art } \\
\text { studio [47]; at a school [55]; old, temporarily unoccupied building [52]; in a university context } \\
\text { [48]; a part of a 'trend' in the West [58], spread all over Western Europe and North America } \\
\text { [47,48,52]; based on Netherlands' experiences, spreading worldwide [9] }\end{array}$ \\
\hline
\end{tabular}

Table A2. Content results: Actors—who and why (not).

\section{Categories and Number of Articles Addressing This}

\section{Results Obtained from the Text}

Subculture \#12

'Critical makers' [43]; maker movement [14,64]; do-it-yourself (DIY) culture [65]; do-it-yourself (DIY) activism [58]; do-it-yourself (DIY) citizens [43]; community workshops [72]; modifiers and fixers movement [14]; local sustainability initiative (LSI) [48,63]; makerspace [56]; repair movement [42]; grassroots movement [61];grassroots innovation movement [62]; grassroots innovation [63]; making culture [58]; culture of repairing [52]; repairing has become public [52]

Change agent \#7

From a 'family responsibility to societal imperative' [12] (p. 55); diverging political positions, contributing to 'the shaping of the (rising) movement of repairers' [42] (p. 638); rethinking of community spaces [44]; internal repair cafés at the nursing faculty [49];'the Computing Repair café' [55]; 'the Bicycle Repair Café [54]; district's transformation [54]; develop practices aimed at sustainability [43]; repair cafés for social change, to lobby for environmental protection, dealing critically with (over)consumption, environmental activism [52] Volunteers (in general) \#5

Especially retired people [43]; often repairers [45]; an artist [43]; a retired teacher [43,47]; librarians [44]; teachers [55]; university employees [43,47]; skilled volunteers [46]. Drivers to engage: Different motivations and ambitions [48] are

complex and include: conservation of resources, waste prevention, appreciation of the apparatus, technical empowerment, having fun repairing things and economic pressure [48] (p. 84) Organisers \#11

Actors in repair cafés and motivating factors \#21
Skilled volunteers [46]; often repairers [45]; librarians [44]; teachers [55]; university employees, retired teachers

[47,48]; artists [48]; 'gatekeepers to circular practices' [56]. Drivers to engage: Educational purpose [55]; give back to their community, encourage others to live more sustainably [46]; test alternatives to uses of public libraries [44]; improvement in 'quality of life' in a district [54]; motives and ambitions vary [48].

Barriers to engage: a lot of work to keep the initiative running [58]; involve a wide range of tasks [52]; the work can be taken for granted [58] Repairers \#6

'Experts' [52]; identifying problems of planned obsolescence regarding electronics [60]; volunteering specialists [48]; volunteer expert [42]; retired and unemployed people [48]; students [52]; 'experts' (bike repair, sewing fabrics, maintenance of laptops, smartphones and radios) [52]; some receive formal training [45]. Motivations to engage: for personal interest [48]; to gain knowledge [48]; fun repairing things [48]; repairing is a positive challenge that keeps retired people young [48]; tasks to do-and possibility to socialise for retired and unemployed people [48]; to help others live more sustainably [68]; to provide service to the community [68]; to help improve product reparability and longevity [68]; to pursue their passion [48](p. 87) Visitors \#5

A variety of people [52]; all age groups, men as well as women, different social backgrounds [48]; students [55]; people with a migration background rarely participate [48]. Motivations to engage: financial [48]; to prolong the lifespan of products [48]; to achieve education/learning goals [55]; to repair things to avoid buying new-not a 'consumer person' [52]; to reduce e-waste [52]; to contribute to a sustainable society [52] 
Table A2. Cont.

\begin{tabular}{|c|c|}
\hline $\begin{array}{c}\text { Categories and Number of Articles } \\
\text { Addressing This }\end{array}$ & Results Obtained from the Text \\
\hline $\begin{array}{l}\text { Drivers to repair } \\
\quad \# 8\end{array}$ & $\begin{array}{l}\text { Environmental and shared value } \\
\text { Increasing volumes of waste [72]; waste reduction [48]; increasing environmental awareness [9]; growing concern } \\
\text { for the environment [72]; resource scarcity [72]; contemporary maker movements [72]; broader behavioural change } \\
\text { [55]; increased awareness [31]; shared value creation or sustainability thinking [14] } \\
\text { Economic } \\
\text { Global economic crisis [9]; business responses to economic opportunities [69]; repair as a CE initiative has a local } \\
\text { dimension to it [25]; accommodate busy lifestyles [61]; lack of financial means to buy new products, saving money } \\
\text { [30]; 'a business response to an economic opportunity' [14] (p. 19). }\end{array}$ \\
\hline $\begin{array}{l}\text { Barriers to repair } \\
\quad \# 17\end{array}$ & 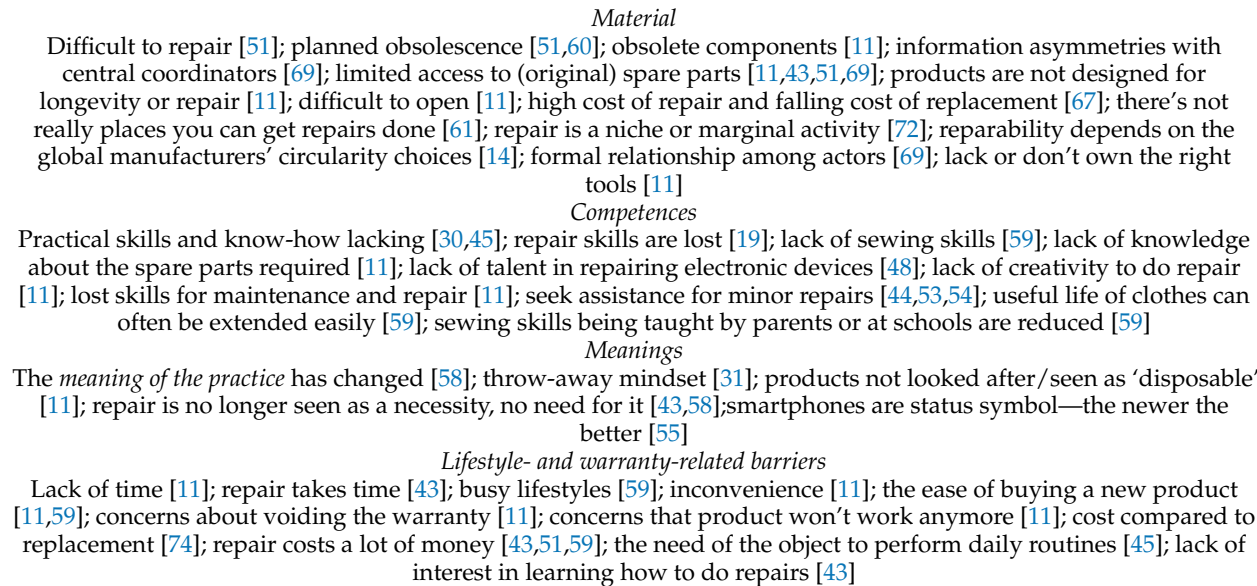 \\
\hline
\end{tabular}

Table A3. Content analysis: The purpose(s) of repair cafés.

\section{Categories and Number of Articles Addressing This}

\section{Results Obtained From the Text}

Waste reduction and product longevity th

Waste reduction and product longevity \#7

A way to reduce waste and to extend the lifetime of products [48]; help improve product reparability and longevity [68]; decrease the amount of trash generated [49]; to reduce e-waste [51]; shared endeavours to combat waste, environmental degradation, shared repair problem [46]; influencing planned obsolescence [60]; 'bottom-up' environmentalism [66]; enables communities to reduce their environmental burden [50]; motivation consumers towards products' repair [12,67]. Strengthen social cohesion \#8

Public sites of repair [42]; a place to meet [30,47,48,53,54]; improve social cohesion among volunteers and visitors [48]; free of charge [42,46,48]; avoidance of costs for people with a low income [48]; people meet to repair [52] Pedagogical aspects of repair movements \#3

A place for 'testing connection between learning skills and long-term change' [42] (p. 644); a place for research and teaching [54]; environmental communication pedagogy [52]; a subject in practical

Purpose(s) \#19 seminars [52]

\section{Revive forgotten skills and hands-on learning \#6}

Revive 'forgotten' technical skills [48]; development of local socio-technical skills [14]; skill-sharing events [58]; a hands-on approach to the pedagogy of repair [42]; where people exchange, access or transfer knowledge [30]; empower people to repair [51]; to share skills [52] Collaborative aspects \#6

Collaboratively repair [45]; shared repairing [46]; 'the idea is to help people to help themselves' [48] (p. 78); help each other to repair broken products [30]; people meet to repair together [52]; the idea is not to provide a 'free service centre' but to help people help themselves free of charge [52]; to learn something together [52]; to become conscious, invite people to learn [65] Service aspects \#6

Workshops with experts [31]; offering self-repair services [31]; a service to the public [46]; a sharing platform [46]; a community space that provides materials, tools and know-how [46]; third-party service providers [69]; autonomous loop operator [69]; professional assistance [54]; a non-market-based solution [14]; a valuable service to the community [68]

\section{References}

1. Ellen MacArthur Foundation. Towards the Circular Economy: Economic and Business Rationale for an Accelerated Transition. Available online: https: / www.ellenmacarthurfoundation.org/assets/downloads/publications/Ellen-MacArthur-FoundationTowards-the-Circular-Economy-vol.1.pdf (accessed on 21 June 2020). 
2. IRP. Re-defining Value-The Manufacturing Revolution. Remanufacturing, Refurbishment, Repair and Direct Reuse in the Circular Economy. A Report of the International Resource Panel. United Nations Environment Programme. 2018. Available online: https:/ / www.resourcepanel.org/reports/re-defining-value-manufacturing-revolution (accessed on 12 August 2020).

3. Cooper, T. Policies for longevity. In Longer Lasting Products. Alternatives to the Throwaway Society; Cooper, T., Ed.; Routledge: London, UK, 2010. [CrossRef]

4. Cooper, D.R.; Gutowski, T.G. The Environmental Impacts of Reuse: A Review. J. Ind. Ecol. 2015, 21, 38-56. [CrossRef]

5. King, A.M.; Burgess, S.C.; Ijomah, W.; McMahon, C.A. Reducing waste: Repair, recondition, remanufacture or recycle? Sustain. Dev. 2006, 14, 257-267. [CrossRef]

6. Duvall, L.; McIntyre, K.; Opsomer, T. Empowering Repair, The Circular Economy 100 (CE100), Ellen MacArthur Foundation, October 2016. Available online: https:/ / www.ellenmacarthurfoundation.org/assets/downloads/ce100/Empowering-RepairFinal-Public.pdf (accessed on 15 August 2020).

7. Bracquené, E.; Brusselaers, J.; Dams, Y.; Peeters, J.; De Schepper, K.; Duflou, J.; Dewulf, W. Repairability Criteria for Energy Related Products. Study in the BeNeLux Context to Evaluate the Options to Extend the Product Life Time Final Report. 2018. Available online: https:/ / benelux.int/files/7915/2896/0920/FINAL_Report_Benelux.pdf (accessed on 4 December 2020).

8. Lechner, G.; Wagner, M.J.; Tena, A.D.; Fleck, C.; Reimann, M. Exploring a regional repair network with a public funding scheme for customer repairs: The 'GRAZ repariert'-case. J. Clean. Prod. 2021, 288, 125588. [CrossRef]

9. Ghisellini, P.; Ulgiati, S. Circular economy transition in Italy. Achievements, perspectives and constraints. J. Clean. Prod. 2020, 243, 118360. [CrossRef]

10. van der Velden, M. 'Fixing the World One Thing at a Time': Community repair and a sustainable circular economy. J. Clean. Prod. 2021, 304, 127151. [CrossRef]

11. Dewberry, E.; Sheldrick, L.; Sinclair, M.; Moreno, M.; Makatsoris, C. Developing scenarios for product longevity and sufficiency. Prod. Lifetimes Environ. 2017, 108-113. [CrossRef]

12. Rosner, D.K. Making Citizens, Reassembling Devices: On Gender and the Development of Contemporary Public Sites of Repair in Northern California. Public Cult. 2014, 26, 51-77. [CrossRef]

13. Routledge. Designing for the Circular Economy; Routledge: Abingdon, UK, 2018.

14. Türkeli, S.; Huang, B.; Stasik, A.; Kemp, R. Circular Economy as a Glocal Business Activity: Mobile Phone Repair in the Netherlands, Poland and China. Energies 2019, 12, 498. [CrossRef]

15. Bocken, N.M.P.; Olivetti, E.A.; Cullen, J.M.; Potting, J.; Lifset, R. Taking the Circularity to the Next Level: A Special Issue on the Circular Economy. J. Ind. Ecol. 2017, 21, 476-482. [CrossRef]

16. Kirchherr, J.; Reike, D.; Hekkert, M. Conceptualizing the circular economy: An analysis of 114 definitions. Resour. Conserv. Recycl. 2017, 127, 221-232. [CrossRef]

17. Report of the World Commission on Environment and Development: Our Common Future. 1987. Available online: http: / / www.un-documents.net/our-common-future.pdf (accessed on 17 November 2017).

18. Geissdoerfer, M.; Savaget, P.; Bocken, N.M.P.; Hultink, E.J. The Circular Economy-A new sustainability paradigm? J. Clean. Prod. 2017, 143, 757-768. [CrossRef]

19. Suárez-Eiroa, B.; Fernández, E.; Méndez-Martínez, G.; Soto-Oñate, D. Operational principles of circular economy for sustainable development: Linking theory and practice. J. Clean. Prod. 2019, 214, 952-961. [CrossRef]

20. Korhonen, J.; Honkasalo, A.; Seppälä, J. Circular Economy: The Concept and its Limitations. Ecol. Econ. 2018, 143, 37-46. [CrossRef]

21. Kalmykova, Y.; Sadagopan, M.; Rosado, L. Circular economy-From review of theories and practices to development of implementation tools. Resour. Conserv. Recycl. 2018, 135, 190-201. [CrossRef]

22. Bocken, N.; Miller, K.; Evans, S. Assessing the Environmental Impact of New Circular Business Models. In Proceedings of the Conference "New Business Models"-Exploring a Changing View on Organizing Value Creation, Toulouse, France, 16-17 June 2016. Available online: https:/ / www.researchgate.net/publication/305264490_Assessing_the_environmental_impact_of_new_ Circular_business_models (accessed on 20 July 2020).

23. Dalhammer, C.; McVeigh, M.K.; Richter, J.L. Planned Obsolescence: Built Not to Last; European Liberal Forum: Brussels, Belgium, 2019. Available online: https://www.liberalforum.eu/wp-content/uploads/2019/11/Planed-Obsecluance_84p_110x178.pdf (accessed on 4 December 2020).

24. Kallis, G.; Kostakis, V.; Lange, S.; Muraca, B.; Paulson, S.; Schmelzer, M. Research on Degrowth. Annu. Rev. Environ. Resour. 2018, 43, 291-316. [CrossRef]

25. Sillanpää, M.; Ncibi, C. The Circular Economy. Circ. Econ. 2019, 1-334. [CrossRef]

26. Wagner, E.; Bracquené, E.; Jaeger-Erben, M. Exploring 14 years of repair records - information retrieval, analysis potential and data gaps to improve reparability. J. Clean. Prod. 2021, 281, 125259. [CrossRef]

27. Potsma, M.; de Boer, S.; van Zeeland, C. Repair Monitor. Analysis Results, 2019; Repair Café International Foundation: Amsterdam, The Netherlands, May 2020. Available online: https:/ / repaircafe.org/en/wp-content/uploads/sites/2/2020/05/RepairMonitor_ analysis_2019_05052020_ENGLISH.pdf (accessed on 7 March 2021).

28. Diddi, S.; Yan, R.-N. Consumer Perceptions Related to Clothing Repair and Community Mending Events: A Circular Economy Perspective. Sustainability 2019, 11, 5306. [CrossRef] 
29. Nazl1, T. Repair motivation and barriers model: Investigating user perspectives related to product repair towards a circular economy. J. Clean. Prod. 2021, 289, 125644. [CrossRef]

30. Rabadjieva, M.; Butzin, A. Emergence and diffusion of social innovation through practice fields. Eur. Plan. Stud. 2019, 28, 925-940. [CrossRef]

31. Dermody, J.; Nagase, Y.; Berger, W. Theorizing self-repairers' worldview-personhood to advance new thinking on extended product lifetimes. Int. J. Consum. Stud. 2020, 44, 435-444. [CrossRef]

32. Van Buren, N.; Demmers, M.; Van Der Heijden, R.; Witlox, F. Towards a Circular Economy: The Role of Dutch Logistics Industries and Governments. Sustainability 2016, 8, 647. [CrossRef]

33. Kristensen, H.S.; Mosgaard, M.A. A review of micro level indicators for a circular economy-moving away from the three dimensions of sustainability? J. Clean. Prod. 2020, 243, 118531. [CrossRef]

34. Borrello, M.; Caracciolo, F.; Lombardi, A.; Pascucci, S.; Cembalo, L. Consumers' Perspective on Circular Economy Strategy for Reducing Food Waste. Sustainability 2017, 9, 141. [CrossRef]

35. Meredith, J. Theory Building through Conceptual Methods. Int. J. Oper. Prod. Manag. 1993, 13, 3-11. [CrossRef]

36. Snyder, H. Literature review as a research methodology: An overview and guidelines. J. Bus. Res. 2019, 104, 333-339. [CrossRef]

37. Webster, J.; Watson, R. Analyzing the past to prepare for the future: Writing a literature review. Mis Q. 2002, 26. [CrossRef]

38. Knapp, J.A. Plugging the "whole": Librarians as interdisciplinary facilitators. Libr. Rev. 2012, 61, 199-214. [CrossRef]

39. Fink, A. Conducting Research Literature Reviews; SAGE: Thousand Oaks, CA, USA, 2014.

40. Briner, R.B.; Denyer, D. Systematic Review and Evidence Synthesis as a Practice and Scholarship Tool. In The Oxford Handbook of Evedence-Based Management; Press, O.U., Ed.; Oxford University Press: New York, NY, USA, 2012; pp. 112-129.

41. Zacho, K.O.; Mosgaard, M. Understanding the role of waste prevention in local waste management: A literature review. Waste Manag. Res. 2016, 34, 980-994. [CrossRef]

42. Graziano, V.; Trogal, K. The politics of collective repair: Examining object-relations in a postwork society. Cult. Stud. 2017, 31, 634-658. [CrossRef]

43. Kannengießer, S. 'I am not a consumer person'-political participation in repair cafés. In (Mis)Understanding Political Participation: Digital Practices, New Forms of Participation and the Renewal of Democracy. Studies in European Communication Research and Education; Wimmer, J., Wallner, C., Winter, R., Oelsne, K., Eds.; Routledge: Abingdon, UK, 2017; pp. 78-94. [CrossRef]

44. Calvert, P. Uncommon Ground: The Place of Cafés in Libraries. Public Libr. Q. 2017, 36, 259-263. [CrossRef]

45. Hielscher, S.; Jaeger-Erben, M. From quick fixes to repair projects: Insights from a citizen science project. J. Clean. Prod. 2021, 278, 123875. [CrossRef]

46. Carrigan, M.; Magrizos, S.; Lazell, J.; Kostopoulos, I. Fostering sustainability through technology-mediated interactions. Inf. Technol. People 2020, 33, 919-943. [CrossRef]

47. Kannengießer, S. Engaging with and reflecting on the materiality of digital media technologies: Repair and fair production. New Media Soc. 2019, 22, 123-139. [CrossRef]

48. Pesch, U.; Spekkink, W.; Quist, J. Local sustainability initiatives: Innovation and civic engagement in societal experiments. Eur. Plan. Stud. 2019, 27, 300-317. [CrossRef]

49. Pattillo, R.E. Meet Me for Lunch at the "Repair Café". Nurse Educ. 2012, 37, 257. [CrossRef]

50. de Angelis, R. Business models and circular business models. In Business Models in the Circular Economy: Concepts, Examples and Theory; de Angelis, R., Ed.; Springer: Berlin/Heidelberg, Germany, 2018. [CrossRef]

51. Park, M. Print to repair: 3D printing and product repair. In Handbook of Sustainable Product Design; Chapman, J., Ed.; Routledge: Abingdon, UK, 2017; pp. 236-249. [CrossRef]

52. Kannengießer, S. Repair cafés: Reflecting on materiality and consumption in environmental communication. In Environmental Communication Pedagogy and Practice; Milstein, T., Pileggi, M., Morgan, E., Eds.; Routledge: Abingdon, UK, 2017 ; pp. 183-194. [CrossRef]

53. Popescu, D.I. Social responsibility and business ethics: IV. Social responsibility and process driven by customer. Qual.-Access Success 2017, 18, 68-72.

54. Dietz, J.; Hoppe, M.; Kollmann, S.; Mansfeld, U. Bike Model District “Alte Neustadt" in Bremen. Iop Conf. Ser. Earth Environ. Sci. 2019, 323, 012086. [CrossRef]

55. Schulte, C.; Krüger, J.; Gödecke, A.; Schmidt, A.-K. The computing repair café: A concept for repair cafés in computing education. In Proceedings of the 13th Workshop in Primary and Secondary Computing Education, WiPSCE '18, Potsdam, Germany, 4-6 October 2018.

56. Prendeville, S.; Hartung, G.; Brass, C.; Purvis, E.; Hall, A. Circular Makerspaces: The founder's view. Int. J. Sustain. Eng. 2017, 10, 272-288. [CrossRef]

57. Charter, M.; Keiller, S. Grassroots innovation and the circular economy. In A Global Survey of Repair Cafés and Hackerspaces; University for the Creative Arts: Farnham, UK, 2014. Available online: https:/ / cfsd.org.uk/site-pdfs/circular-economy-andgrassroots-innovation/Survey-of-Repair-Cafes-and-Hackerspaces.pdf (accessed on 10 March 2021).

58. Hector, P. Making and repairing places for making and repairing. Strat. Des. Res. J. 2018, 11, 115-124. [CrossRef]

59. Kohtala, C. Making "Making" Critical: How Sustainability is Constituted in Fab Lab Ideology. Des. J. 2016, 20, 375-394. [CrossRef]

60. Proske, M.; Winzer, J.; Marwede, M.; Nissen, N.F.; Lang, K.-D. Obsolescence of Electronics-the Example of Smartphones; IEEE: Manhattan, NY, USA, 2016; pp. 1-8. 
61. McLaren, A.; Goworek, H. Investigating the Relationship Between Consumer Attitudes and Sustainable Fashion Product Development. In Sustainability in Fashion; Springer: Berlin/Heidelberg, Germany, 2017; pp. 171-192.

62. Smith, A.; Fressoli, M.; Abrol, D.; Arond, E.; Ely, A. Grassroots Innovation Movements; Routledge: New York, NY, USA, 2016.

63. Mouzakitis, Y.; Adamides, E.D. The Bottom-Up Side of Eco-innovation: Mapping the Dynamics of Sustainable Grassroots Innovations. Intell. Interact. Multimed. Syst. Serv. 2019, 155, 61-71. [CrossRef]

64. Unterfrauner, E.; Shao, J.; Hofer, M.; Fabian, C.M. The environmental value and impact of the Maker movement-Insights from a cross-case analysis of European maker initiatives. Bus. Strat. Environ. 2019, 28, 1518-1533. [CrossRef]

65. Raphael, C. Engaged Communication Scholarship for Environmental Justice: A Research Agenda. Environ. Commun. 2019, 13, 1087-1107. [CrossRef]

66. Haderer, M. Revisiting the Right to the City, Rethinking Urban Environmentalism: From Lifeworld Environmentalism to Planetary Environmentalism. Soc. Sci. 2020, 9, 15. [CrossRef]

67. Sabbaghi, M.; Cade, W.; Behdad, S.; Bisantz, A. The current status of the consumer electronics repair industry in the U.S.: A survey-based study. Resour. Conserv. Recycl. 2017, 116, 137-151. [CrossRef]

68. Nascimento, S.; Pólvora, A. Maker Cultures and the Prospects for Technological Action. Sci. Eng. Ethic 2018, 24, 927-946. [CrossRef]

69. Hansen, E.G.; Revellio, F. Circular value creation architectures: Make, ally, buy, or laissez-faire. J. Ind. Ecol. 2020, $24,1250-1273$. [CrossRef]

70. Borrello, M.; Pascucci, S.; Caracciolo, F.; Lombardi, A.; Cembalo, L. Consumers are willing to participate in circular business models: A practice theory perspective to food provisioning. J. Clean. Prod. 2020, 259, 121013. [CrossRef]

71. Meißner, M. Repair is care?-Dimensions of care within collaborative practices in repair cafes. J. Clean. Prod. 2021, 299, 126913. [CrossRef]

72. Sung, K.; Cooper, T.; Kettley, S. Developing interventions for scaling up UK upcycling. Energies 2019, 12, 2778. [CrossRef]

73. EU. Behavioural Study on Consumers' Engagement in the Circular Economy_Final Report; EU: Brussels, Belgium, 2018.

74. Hepp, A. Pioneer communities: Collective actors in deep mediatisation. Media Cult. Soc. 2016, 38, 918-933. [CrossRef] 